\title{
A DIMENSÃO DA TEOLOGIA PRÁTICA NA AÇÃO ECLESIOLÓGICA NO CONTEXTO DA COMUNIDADE DE RISCO SOCIAL: UMA PROPOSTA PARA O DESENVOLVIMENTO HUMANO ${ }^{1}$
}

\author{
THE DIMENSION OF PRACTICAL THEOLOGY IN ECCLESIOLOGICAL ACTION IN THE \\ CONTEXT OF THE COMMUNITY AT SOCIAL RISK: A PROPOSAL FOR HUMAN \\ DEVELOPMENT
}

\author{
Flavio da Silva Chaves*
}

\section{Resumo:}

O presente artigo tem como objetivo apresentar a Teologia Prática enquanto proposta para a ação eclesiológica no contexto da comunidade de risco social. Busca-se distinguir conceitualmente a Teologia Dogmática da Teologia Prática, demonstrar os dilemas existenciais enfrentados pela comunidade de risco social e discutir as ações eclesiológicas nesse contexto na perspectiva da Teologia Prática, tendo como princípio a Teologia da Esperança, em Jürgen Moltmann.

Palavras-chave: Teologia Prática; Ação Eclesiológica; Comunidade de Risco Social.

\begin{abstract}
:
This article aims to present Practical Theology as a proposal for ecclesiological action in the context of the social risk community. It seeks to distinguish conceptually the Dogmatic Theology of Practical Theology, to demonstrate the existential dilemmas faced by the community of social risk and to discuss the ecclesiological actions in this context from the perspective of Practical Theology, having as principle the Theology of Hope in Jürgen Moltmann.
\end{abstract}

Keywords: Practical Theology; Ecclesiological Action; Community of Social Risk.

\section{Introdução}

Apresentar a Teologia enquanto instrumento de ação social requer em primeira instância um olhar para as mudanças ocorridas em torno da religião e, respectivamente, para os problemas decorrentes da sociedade contemporânea. Ludwig Feuerbach argumenta que "o medo foi que criou

1 Enviado em: 23.05.2018. Aceito em: 25.05.2020.

* Mestre em Ciências das Religiões (FUV); graduado em Psicologia (UNESA); graduado em Teologia (FUV); pós graduando em Psicoterapia Existencial e Gestalt Terapia (ISECENSA). Professor de Introdução ao Antigo Testamento e Teologia Bíblica do Antigo Testamento na Faculdade Batista do Estado do Rio de Janeiro. Psicólogo Clinico e Pastor da Segunda Igreja Batista do Parque Aldeia, em Campos dos Goytacazes, RJ. E-mail: flavio.chaves.silva@hotmail.com

Protestantismo em Revista | São Leopoldo | v. 45, n. 02 | p. 20-36| Jul./dez. 2019

Disponível em: <http://periodicos.est.edu.br/index.php/nepp> 
deuses no mundo" 2. Em sua concepção, a felicidade é um instinto humano, ainda que criado pela fantasia, porque o homem não suporta o mundo real.

Em sua argumentação, "a religião é, pois, a fase infantil da humanidade" ${ }^{3}$, critica seguida por Sigmund Freud, o pai da Psicanálise e contestada por Fraas ${ }^{4}$, que não nega a relação entre religião e produção da fantasia humana. Todavia, afirma que, "depreciar essa atividade da fantasia de antemão como produção de imagens delirantes e, assim, como neurótica precisa ser considerado uma atitude precipitada" 5 . Neste contexto, a Teologia se apresenta enquanto fonte de saúde pública ${ }^{6}$, dialogando de forma interdisciplinar ${ }^{7}$ com outros campos do saber, discutindo temas relevantes na sociedade, superando o divórcio entre fé e vida que se perpetuaram com o advento do lluminismo, no Século XVIII.

Quanto à sociedade contemporânea, dois fatos contribuem para a inserção do discurso teológico na prática social. Primeiro é o seu caráter de urgência e demandas emergenciais. Han $^{8}$ ao considerar que "cada época tem as suas enfermidades fundamentais" afirma que "doenças neuronais como a depressão, transtorno de déficit de atenção com síndrome de hiperatividade (Tdah), Transtorno de personalidade limítrofe (TPL) ou a Síndrome de Burnout (SB) determinam a paisagem patológica do começo do século $\mathrm{XXI}^{\prime 9}$. Segundo é o elemento de abertura no campo cientifico para a inserção de novos saberes, conforme prescrito por Morin ${ }^{10}$ diante da crise pandêmica do coronavírus. Nessa visão, permanece o caráter dialógico dos saberes em detrimento a massificação e determinismo científico.

O Brasil ocupou o septuagésimo quinto lugar no ranking global de desenvolvimento humano em 2014, denominado "bom índice de desenvolvimento", apresentando melhoras de 0.0001 no Índice de Desenvolvimento Humano (IDH), mantendo a posição 79 entre 189 países. Na América do Sul, é o quinto maior país em IDH, ficando atrás de Chile, Argentina, Uruguai e Venezuela (BRASIL, 2014) ${ }^{11}$. Parece uma característica promissora, todavia, no Índice de Desenvolvimento Humano ajustado a desigualdade, "o Brasil é o 3o país da América do Sul que mais perde no IDH

2 FEUERBACH, Ludwig. A essência do cristianismo. Petrópolis, RJ: Vozes, 2007. p. 8. “Nascido em Rechenberg em 1804, Ludwig Andreas Feuerbach foi um filósofo alemão conhecido pelo estudo da teologia humanista. Ele foi aluno do filósofo Hegel, porém, abandonou os estudos hegelianos para, em 1828, iniciar estudos em ciências naturais. Após dois anos de análise, publica "Pensamentos Sobre a Morte e Imortalidade" de forma anônima. Foi nesta obra que iniciou suas investidas contra a ideia de imortalidade. Para Feuerbach, após o falecimento, todas as características humanas são carcomidas pela natureza". Disponível em: http://www.infoescola.com/filosofos/ludwig-feuerbach/ Acesso em: 05 Fev. 2016.

3 FEUERBACH, 2007, p. 9.

4 FRAAS, Hans-Jurgen. A religiosidade humana: compêndio de psicologia da religião. Tradução de Ilson Kayser e Werner Fuchs. 2. ed. São Leopoldo: Sinodal, 1997, p. 38-72.

5 FRAAS 1997, p. 50.

6 VILLAS BOAS, Alex. Em busca de uma teologia pública da saúde. Horizonte, Belo Horizonte, v. 14, n. 41, p. 89-121, Jan./Mar. 2016.

7 PUC-RIO, Certificação Digital No 0220971/CA. Teologia e interdisciplinaridade. Disponível em: https://www.maxwell.vrac.puc-rio.br/10454/10454 4.PDF. Acesso em: 18 Fev. 2020.

8 HAN, Byung-Chul. Sociedade do cansaço. Tradução de Enio Paulo Giachini. Petrópolis: Vozes, 2015, p. 7.

9 HAN, 2015, p. 7.

10 MORIN, Edgar. As certezas são uma ilusão por CNRS / Le Journal por Francis Lecompte - 09.04.2020. Fronteiras do Pensamento. Disponível em: https://www.fronteiras.com/entrevistas/edgar-morin-as-certezas-sao-uma-ilusao. Acesso em: 09 Mai. 2020.

11 BRASIL, 2014. Ranking IDH Global 2014. Fonte: Relatório de Desenvolvimento Humano 2015. Disponível em: http://www.br.undp.org/content/brazil/pt/home/idho/rankings/idh-global.html. Acesso em: 14 Set. 2018.

Protestantismo em Revista | São Leopoldo | v. 45, n. 02 | p. 20-36| Jul./dez. 2019

Disponível em: <http://periodicos.est.edu.br/index.php/nepp> 
devido ao ajuste realizado pela desigualdade, ficando atrás do Paraguai $(25,5 \%)$ e da Bolívia $(25,8 \%)^{\prime \prime 12}$.

As diferenças salariais entre os sexos, onde a renda per capita da mulher é $47 \%$ menor que a do homem, mantem uma diferença de IDH do homem para a mulher. "No Brasil, o IDH dos homens fica em 0,761 e o das mulheres em $0,755^{\prime 13}$. Ressalta-se que as desigualdades se fazem presente em escala global, fato constatado nos Indicadores e Índices de Desenvolvimento Humano pelo Programa das Nações Unidas para o Desenvolvimento (PNUD). Constata-se que embora haja uma melhor qualidade de vida, continua o caráter de exclusão, principalmente, a de gênero ${ }^{14}$.

Dentre as contribuições da PNUD (órgão que trabalha em aproximadamente 170 países), para o desenvolvimento sustentável está a "erradicação da pobreza e a redução de desigualdades e da exclusão social". No Brasil, o projeto da PNUD para 2030 é ajudar o Brasil a se tornar um país mais sustentável. Na consolidação deste projeto busca-se "a participação de populações vulneráveis nas políticas públicas e no diálogo democrático"15.

Sendo assim, a pesquisa justifica-se por apresentar uma teologia com proposta de relevância e esperança, sob a ótica de quem vive e sofre os mais terríveis dilemas da vida: a comunidade de risco social. Sob esta perspectiva, a teologia surge como esperança, um renascer, um novo horizonte que impulsiona, abrindo portas e motivando para a vida. O objetivo é contribuir, mediante a reflexão teológica, para a humanização do indivíduo e para a equidade social.

Para reacender as chamas dessa importância e suas perspectivas para o século XXI, é necessário indagar: o que é Teologia Prática e em que ela se diferencia da Teologia Dogmática? Quais os problemas e dilemas enfrentados pelas comunidades de risco social? De que forma a Teologia seria relevante para o contexto e problemas enfrentados na comunidade de risco social? Pensando nisso, será possível refletir no tema proposto.

\section{Por uma Teologia Prática e não Dogmatizada: Um Caminho para a Ação Eclesiológica na Contemporaneidade}

O que é Teologia Prática e o que seria uma Teologia Dogmatizada? Por que optar por uma Teologia Prática em detrimento da Dogmática? Esses dois questionamentos servem de norte para o que se propõe neste primeiro tópico. A proposta é apresentar a Teologia Prática enquanto caminho para uma ação eclesiológica relevante na contemporaneidade.

Definir o termo teologia é ambíguo. Nos anos 50 acontecem mudanças geopolíticas significativas na ordem mundial das nações. Neste cenário surgem os termos 'Terceiro Mundo' e 'países subdesenvolvidos' os quais impõem, no âmbito teológico, a necessidade e urgência de rever conceitos e contextualizá-las no intuito de promover a cidadania e dirimir as desigualdades na América Latina, no Caribe, na África, na Ásia e na Oceania Meridional ${ }^{16}$, ou seja, uma Teologia da

12 BRASIL ${ }^{1}$, 2018. Brasil mantém tendência de avanço no desenvolvimento humano, mas desigualdades persistem. Posted on 14 de Setembro de 2018.2 Disponível em: http://www.br.undp.org/content/brazil/pt/home/presscenter/articles/2018/brasil-mantem-tendencia-de-avancono-desenvolvimento-humano--mas.html. Acesso em: 14 Set. 2018.

13 BRASIL ${ }^{1}, 2018$.

14 BRASIL ${ }^{1}, 2018$.

15 BRASIL', 2018. Sobre o PNUD. Disponível em: http://www.br.undp.org/content/brazil/pt/home/operations/about undp.html. Acesso em: 14 Set. 2018.

16 SANCHES, Sidney de Moraes. A contextualização da teologia: conceitos, história, tensões, métodos e possibilidades. Revista Tecer, Belo Horizonte, vol. 2, no 3, novembro 2009.

Protestantismo em Revista | São Leopoldo | v. 45, n. 02 | p. 20-36| Jul./dez. 2019

Disponível em: <http://periodicos.est.edu.br/index.php/nepp> 
cultura e para a cultura, desvinculando-se de uma prática discursiva descontextualizada e de dominação ocidental. Essa perspectiva alterou significativamente o conceito de educação teológica em 1970 quando, mediante uma carta, Elweel suscitou uma pesquisa entre os termos "Teologia Dogmática ou Contextual"17:

Nesta carta, ele colocou a possibilidade de uma teologia contextual, também denominada experimental, 'que brota do cenário e pensamento históricos contemporâneos, em contraste com as teologias sistemáticas ou dogmáticas, cujo fundamento pode ser descoberto na tradição bíblica e nas declarações confessionais baseadas no texto bíblico' ${ }^{18}$.

As Igrejas devem servir a missão e serem orientadas para uma perspectiva local, o que pressupõe como um dos fundamentos para uma Teologia Prática e não Dogmática. Dependendo do termo utilizado, a prática eclesiológica poderá adotar caminhos equivocados. Em sua liturgia e forma de conceber a ideia sobre Deus, pode promover a exclusão e/ou a inclusão do ser humano no seu contexto. De outro modo, a Teologia pode ser um instrumento confessional ou público. 0 primeiro pertence ao mundo das religiões, de suas instituições, enquanto o segundo, "preocupa-se com o bem estar da sociedade, não somente como os membros que frequentam as fileiras da Igreja"19 ${ }^{19}$, depreendendo-se que, a Teologia Dogmática é um mecanismo confessional e não público.

É possível verificar essa assertiva nas obras de Louis Berkhoff ${ }^{20}$, um clássico da teologia presbiteriana e Jhon L. Dagg ${ }^{21}$, clássico da teologia batista, muito utilizado por estudantes de teologia para os concílios. Segundo Berkhof, "[...] a Teologia é o conhecimento sistematizado de Deus, de quem, por meio de quem, e para quem são todas as coisas" ${ }^{22}$. Mas qual é o conhecimento sistematizado de Deus? Ou, quem é Deus? Esse conhecimento sistematizado e até mesmo a conceituação de Deus perpassa pela lente dogmática de quem a promulga, o que pode caracterizar ou não o caráter de inclusão ou exclusão de pessoas por meio da absolutização da verdade.

Nesse sentido, "[...] a igreja cristã confessa, por um lado, que Deus é o Incompreensível, mas também, por outro lado, que Ele pode ser conhecido e que conhecê-lo é um requisito absoluto para a salvação" 23 . A teologia, nessas palavras, busca provar uma verdade e categorizar as pessoas por meio dessa verdade. Isso parece ser claro na doutrina da aplicação da obra de redenção ${ }^{24}$.

Por outro lado, é salutar a relação entre a cristologia e a soteriologia ${ }^{25}$. O problema é a Ordo Salutis (a Ordem da Salvação) ${ }^{26}$. "A soteriologia reformada (calvinista) toma o ponto de partida na união estabelecida no pactum salutis (aliança e redenção) entre Cristo e aqueles que o Pai Lhe deu, em virtude da qual há uma imputação eterna da justiça de Cristo àqueles que Ihe

5 BERKHOF, 1990, p. 415. Ou seja, é possível a salvação mediante a aplicação da obra de Cristo e a apropriação da salvação pelo pecador.

26 BERKHOF, 1990, p. 416. "A ordo salutis descreve o processo pelo qual a obra de salvação, realizada em Cristo, é concretizada subjetivamente nos corações e vidas dos pecadores. Visa a descrever, em sua ordem lógica e também em sua interrelação, os vários movimentos do Espírito Santo na aplicação da obra de redenção. A ênfase não recai no que o homem faz, ao apropriar-se da graça de Deus, mas no que Deus faz, ao aplica-la".

Protestantismo em Revista | São Leopoldo | v. 45, n. 02 | p. 20-36| Jul./dez. 2019 
pertencem"27. Por essa linha de raciocínio, segue a doutrina da eleição no calvinismo circunscrita ao dogma da igreja. O mesmo ocorre no conceito luterano, no conceito católico romano e no conceito arminiano. $^{28}$

No estudo da teologia de Dagg são estabelecidas verdades centrais acerca de Deus. Não há problema nisso. A questão é quando se faz dessas verdades um elemento de dominação e opressão do povo, definindo o que é e o que não é aceitável por Deus. Em sua definição afirma-se que Deus é onipresente, onisciente e onipotente, ou seja, Deus está em todos os lugares, Deus sabe todas as coisas e Deus pode fazer tudo quanto Ele quiser ${ }^{29}$. Como afirmar, dogmaticamente, que Deus pode fazer tudo quanto Ele quiser?

Neste momento que a humanidade atravessa uma mudança de época, diagnosticada de formas diferentes e até antagônicas, com diferentes cosmovisões que advogam sua verdade muitas vezes de forma absoluta, não raras vezes fundamentalista, as Igrejas Cristãs precisam responder ao desafio de falar de Deus, entendido esse "falar de Deus", como anunciar o Deus revelado por Jesus Cristo, para o ser humano que vive em contexto urbano. ${ }^{30}$

Percebe-se que a forma como se interpreta a Bíblia influencia diretamente no pensamento teológico ${ }^{31}$ com os seus desdobramentos na vida cotidiana, demandando sempre novas significações para novos contextos. É a proposta de Alessandro Rodrigues Rocha ao definir a Teologia Sistemática ${ }^{32}$ como uma teologia que se liberte do arcabouço teórico do passado, descortinando novo campo epistemológico para a sua atuação na contemporaneidade. Por definição, apropriando-se das palavras de Libânio, afirma que as principais ênfases da teologia dogmático-sistemática foram:

[...] "sistematizar, definir, expor e explicar as verdades reveladas", não só visando a "mostrar o que estava incluído no universo da fé, mas também a excluir as posições doutrinárias e oposição à fé, condenando os erros, resolvendo as dificuldades, refutando as falácias dos adversários". Ou, em outras palavras, afirmando a univocidade da verdade teológica. ${ }^{33}$

Qual o principal problema dessa teologia para a modernidade que fez surgir a necessidade de uma nova forma de fazer teologia? Acerca desse assunto, Rocha comenta:

Essa abordagem metodológica, com sua forte ênfase apologética a serviço da ortodoxia, criou um corpo doutrinário, um sistema totalizador dos temas da fé que, num primeiro momento, possibilitou o diálogo da teologia cristã com a cultura à sua volta. Mas foi

27 BERKHOF, 1990, p. 418.

28 BERKHOF, 1990, p. 420-423.

29 DAGG, 1990, p. 50-58.

30 BROTTO, Julio Cezar de Paula. O eternamente novo no mesmo evangelho: implicações teológico-pastorais para a evangelização das tribos urbanas de rosto underground. Tese (doutorado) - Pontifícia Universidade Católica do Rio de Janeiro, Departamento de Teologia, 2016, p. 6. Disponível em: https://www.maxwell.vrac.pucrio.br/27184/27184.PDF. Acesso em: 20 Mai. 2020.

31 SMITH, Ralph L. Teologia do antigo testamento: história, método e mensagem. São Paulo: Vida Nova, 2001, p. 2266. O autor apresenta o caminho para a formação da teologia bíblica do antigo testamento, desvinculando da dogmática. Dessa forma, a interpretação bíblica sofreu influência na Idade Média, na Renascença até chegar ao Iluminismo.

32 ROCHA, Alessandro Rodrigues. Teologia sistemática no horizonte pós-moderno: um novo lugar para a linguagem teológica. São Paulo: Editora Vida, 2007. p. 15-20; p. 63-69.

33 ROCHA, 2007, p. 64.

Protestantismo em Revista | São Leopoldo | v. 45, n. 02 | p. 20-36| Jul./dez. 2019

Disponível em: <http://periodicos.est.edu.br/index.php/nepp> 
lentamente perdendo o impulso, à medida que ia-se tornando reativa, ou seja, que ia-se limitando à defesa de seus postulados sem os colocar em contato com novas realidades. ${ }^{34}$

A proposta é uma teologia dogmático-sistemática que busque desvelar sentidos e não definições, exemplificada a partir do mito e na desconstrução do pensamento metafísico dos filósofos ${ }^{35}$. O desafio é a descolonização da teologia sendo "necessário buscar também uma descolonização da Bíblia e do próprio conceito de "Palavra de Deus", bem como dos dogmas da Inspiração e da Revelação" ${ }^{36}$.

Nesta direção Valtair A. Miranda diz que o objeto de pesquisa da teologia não é Deus, mas as afirmações sobre Ele, as expressões de fé37. Embora o seu foco seja a Teologia Bíblica, apresenta, de forma concisa, as diferenciações entre Teologia Histórica, Teologia Sistemática e Teologia Prática. Assim, a missão do teólogo sistemático "[...] é elaborar um sistema teológico que expresse sua fé ou a fé de determinada corrente cristã" ${ }^{38}$, enquanto que o teólogo prático "[...] deve sempre mostrar a diferença que as suas conclusões fazem na vida cotidiana dos fiéis" 39 . A proposta desta pesquisa é a Teologia Prática como caminho para uma ação eclesiológica relevante na atualidade. Mas o que é Teologia Prática? Júlio Paulo Tavares Zabatiero afirma:

Teologia Prática é discurso crítico e construtivo sobre a ação cristã no mundo presente. Fundamenta-se no discernimento da ação de Deus no mundo presente, e se constrói em diálogo - crítico e construtivo - com os discursos sobre a ação presente. A racionalidade da Teologia Prática é a de uma teoria crítico-discursiva da ação; e sua finalidade é contribuir para o aperfeiçoamento da ação cristã no mundo, em resposta crística - na energia do Espirito Santo - à ação presente de Deus no mundo. ${ }^{40}$

É o discurso da ação cristã no mundo. É discurso crítico. É discurso construtivo. É discurso "[...] cujo paradigma da ação não se encontra na Igreja, mas em Jesus Cristo" ${ }^{41}$, em que o teólogo é a comunidade cristã. Por ser discurso crítico não é absolutizante, "A ação cristã deve ser acompanhada constantemente do discernimento do agir da comunidade cristã, na busca de acertar os nossos erros e os nossos acertos" ${ }^{\prime 2}$. Mas, igualmente, é discurso construtivo, pois não busca apenas apontar erros, busca responder de forma positiva a ação de Deus. Nesse sentido, a Teologia Prática

[...] visa construir comunidade de reconciliação, amor e justiça. As comunidades cristãs serão, assim, protótipos do Reino de Deus, serão primícias do Reino, espaços onde as

34 ROCHA, 2007, p. 65.

35 ROCHA, 2007, p. 23-69.

36 DIETRICH, Luiz José. A descolonização da Bíblia, da "Palavra de Deus": O desafio primeiro e urgente para uma teologia descolonial. ReBiblica, Porto Alegre, v. 1, n. 1, p. 19-37, jan.-jun. 2018, p. 19.

37 MIRANDA, Valtair A. Fundamentos da teologia bíblica. São Paulo: Mundo Cristão, 2011. p. 11-17.

38 MIRANDA, 2011, p. 12.

39 MIRANDA, 2011, p. 12.

40 ZABATIERO, Júlio Paulo Tavares. A Teologia Prática e seu lugar na Igreja. Revista Teologia Prática - FATE-BH, Belo Horizonte, v. 1, n.1, p. 7-15, 2002.

41 ZABATIERO, 2002, p. 9.

42 ZABATIERO, 2002, p. 9.

Protestantismo em Revista | São Leopoldo | v. 45, n. 02 | p. 20-36| Jul./dez. 2019

Disponível em: <http://periodicos.est.edu.br/index.php/nepp> 
pessoas poderão encontrar amizade, companheirismo, sentido para a vida e, especialmente, poderão encontrar Deus presente e atuante. ${ }^{43}$

Sendo assim, a Teologia Prática caminha em diálogo com o contexto no qual está inserida. É um dar as mãos ao sofrimento, a dor e as lágrimas do ser humano. "Prática é o modo de ser da teologia" ${ }^{44}$. É a teologia em ação, exemplificada no paradigma do Bom Samaritano registrado no Evangelho de Lucas 10.25-37. Desta forma, "[...] fazer teologia, como nos recorda este episódio do Evangelho, não significa especular, mas encontrar novos estímulos para seguir a Jesus Cristo e dar testemunho das boas novas de seu reino" 45 .

Lothar Carlos Hoch, afirma que a Teologia Prática chegou para corrigir um erro de distorção ${ }^{46}$, no sentido do distanciamento entre a formação acadêmica dos pastores e a sua prática eclesiológica. Sua proposta é que a Teologia Prática, ensinada nos seminários, encurte o caminho que a separa da pastoral. Assim, a Teologia Prática surge da necessidade de se criar uma disciplina teológica capaz de estabelecer uma relação adequada entre a teologia acadêmica e a prática da fé. Por esse viés, "[...] a fé cristã não se limita à contemplação ou ao ato de assentir a um sistema de verdades reveladas, mas consiste em se envolver com Jesus, sua palavra e ação e em segui-la em sua trajetória de cruz e sofrimento. E como tal só poderá ser teologia prática" ${ }^{47}$. Dessa forma,

A tarefa primeira da Teologia Prática consiste, por isso mesmo, em encontrar o seu lugar específico, a partir do qual possa dar a sua contribuição própria tanto à teologia como à igreja e, muito especialmente, aos desafios que a sociedade, no nosso caso a sociedade latino-americana, Ihe colocam. ${ }^{48}$

Essa sociedade que se apresenta enquanto desafio para a Teologia Prática vive um processo de fragmentação. Falta justiça. Num mundo globalizado a miséria humana está aqui e em todos os lugares, gerando uma sociedade impotente em escolher o próprio destino ${ }^{49}$. "Num planeta negativamente globalizado, todos os principais problemas - os meta problemas que condicionam o enfrentamento de os outros - são globais e, sendo assim, não admitem soluções locais" 50 . As sociedades abertas, fruto da globalização, têm gerado medo e insegurança aos seus habitantes. Trata-se de um problema frequente das comunidades de risco social que, além de sofrerem com altos índices de violência, sofrem com o abuso de substância psicoativa e constante perda da autoimagem.

Constata-se mediante essas considerações que vivemos num novo contexto históricosocial. Nesse novo momento é preciso diálogo entre todas as instâncias para promover o bem-estar social, assim sendo, por que Teologia Prática e não Teologia Dogmática? Por causa do seu caráter contextual e de missão, o que difere da Dogmática que, conforme Rocha aponta, necessita de reformulações metodológicas que possibilitem ressignificações para o contexto atual ${ }^{51}$. $E$ ainda, a

43 ZABATIERO, 2002, p. 9.

44 ZABATIERO, Júlio. Fundamentos da teologia prática. São Paulo: Mundo Cristão, 2005, p. 25.

45 ZABATIERO, 2005, p. 26.

$46 \mathrm{HOCH}$, Lothar Carlos. O lugar da teologia prática como disciplina teológica In: SCHNEIDER-HARPPRECHT, Christoph; ZWETSCH, Roberto E.; HOCH, Lothar Carlos. Teologia prática no contexto da América Latina. 3. ed. revista e ampliada São Leopoldo, RS: Sinodal, 2011, p. 23-35.

$47 \mathrm{HOCH}, 2016$, p. 26.

$48 \mathrm{HOCH}, 2016$, p. 27.

49 BAUMAN, Zygmunt. Tempos líquidos. Rio de Janeiro: Zahar, 2007, p. 11-32.

50 BAUMAN, 2007, p. 31.

51 ROCHA, 2007, p. 23-69.

Protestantismo em Revista | São Leopoldo | v. 45, n. 02 | p. 20-36| Jul./dez. 2019

Disponível em: <http://periodicos.est.edu.br/index.php/nepp> 
Teologia Prática surge como uma ponte para dirimir distância entre o academicismo e a prática pastoral, tornando a missão eclesiológica no mundo mais eficiente e dinâmica, o que inclui, especificamente, a comunidade de risco social, assunto que nos deteremos a seguir.

\section{A Comunidade de Risco Social e os Seus Conflitos para o Ser Humano}

Antes de considerar as perspectivas da Teologia Prática e sua ação missiológica no contexto da comunidade de risco social, é necessário um rápido olhar para os principais problemas enfrentados por essa comunidade. Esse será o objetivo deste tópico ${ }^{52}$. Maria Tereza Freitas Campos define o termo comunidade tanto do ponto de vista geográfico quanto psicossocial. Quanto ao primeiro, pode ser o bairro, enquanto o segundo relaciona-se ao "[...] lugar em que grande parte da vida cotidiana é vivida" 53 . Não há uma definição clara sobre o que seja risco social.

$\mathrm{Na}$ literatura, o termo aparece adjunto ao conceito de vulnerabilidade social. Rosane Janczura apresenta algumas conclusões sobre esse assunto, afirmando que esses termos podem ser entendidos de acordo com os contextos-sociais, são conceitos distintos, mas intrinsecamente ligados e não estão restritos às comunidades de periferia. "A sociedade pós-industrial é uma sociedade de risco, principalmente pelos efeitos que a tecnologia e a globalização econômica produziram" 54 . Assim, "[...] o primeiro conceito se refere à situação de grupos, e o segundo deve ser usado para a situação fragilizada de indivíduos" 55 .

Logo, a comunidade de risco social seria qualquer grupo que, devido às pressões externas e/ou internas, seja a comunidade da periferia ou a comunidade pós-industrial, seja a criança ou o idoso, seja o adolescente ou o jovem, estejam comprometidos no seu desenvolvimento físico, psicológico, social e espiritual.

Os fatores que comprometem esse desenvolvimento podem estar associados à violação dos direitos humanos, com desdobramento para a estrutura familiar. Nesse sentido, Soare ${ }^{56}$, numa pesquisa na comunidade do $S$, no Baixo Roger, no município de João Pessoa, relaciona risco social ao descaso, à exclusão social, à péssima condição de vida no tocante à moradia, alimentação, educação, saúde e saneamento básico.

Nessa direção Amparo et al. ${ }^{57}$, segundo pesquisa com jovens e adolescentes entre 13 e 27 anos cursando o ensino médio, aponta como indicadores de risco aspectos relativos ao Índice de Desenvolvimento Humano e à renda familiar. Desta forma, "[...] abandono, negligência, conflitos familiares, convivência com pessoas que fazem uso abusivo de álcool e outras drogas, além de todas as formas de violência (física, sexual e psicológica), configuram violação de direitos infanto-

52 CHAVES, Flávio da Silva Chaves. A relevância da psicologia comunitária no contexto pós-moderno. Universidade Estácio de Sá, Campos dos Goytacazes, 2012.

53 CAMPOS, Maria Tereza Freitas. Psicologia Comunitária: da solidariedade à autonomia. Petrópolis: Vozes, 2007, p. 9.

54 JANCZURA, Rosane. Risco ou vulnerabilidade social? Textos \& Contextos, Porto Alegre, v. 11, n. 2, p. 301-308, ago./dez.2012. O texto apresenta as variações e diferenças conceituais entre risco e vulnerabilidade social. Assim, os termos se diferenciam na linguagem de um economista, dos sociólogos, dos psicólogos e de outros cientistas.

55 JANCZURA, 2012, p. 307.

56 SOARES, Maria de Lourdes. A exclusão de comunidades em situação de vulnerabilidade e de risco social: o caso da comunidade do $\mathrm{S}$. Disponível

em: http://www.cibs.cbciss.org/arquivos/A\%20EXCLUSIO\%20DE\%20COMUNIDADES\%20EM\%20SITUACAO\%20DE\%20V ULNE. Acesso em: 25 Jul. 2014.

57 AMPARO, Deise Matos do. Adolescentes e jovens em situação de risco psicossocial: redes de apoio social e fatores pessoais de proteção. Disponível em: http://www.scielo.br/epsic. Acesso em: 25 Jul. 2014.

Protestantismo em Revista | São Leopoldo | v. 45, n. 02 | p. 20-36| Jul./dez. 2019 
juvenis"58. Isso parece nítido na pesquisa de Leticia Marin-Léon, em que a autora relaciona o aumento da violência no município de Campinas à violação desses direitos. Segundo ela,

[...] as condições socioeconômicas desfavoráveis associam-se a violência [...] Ser do sexo feminino e residir em bairro de nível socioeconômico associou-se de forma significativa à percepção de maior gravidade de tráfico de drogas, abuso de drogas, abuso de álcool, abuso de crianças e esposa, desemprego e pobreza. ${ }^{59}$

Considera-se vulnerabilidade social pessoas e lugares que estão expostos à exclusão social, ou seja, famílias, indivíduos sozinhos com sinais de desnutrição, condições precárias de moradia e saneamento. A vulnerabilidade e o risco social apresentam-se como sinônimos de pobreza, sendo uma consequência da outra, porém, esta não é a única forma de analisar a questão. Segundo Ida Timóteo Lemos, a vulnerabilidade não se aplica apenas ao contexto socioeconômico como justificativa para os mais variados dilemas de delinquência juvenil em que a sociedade tem sido exposta. Um estudo sobre risco social e psicopatologia em adolescentes com percurso delinquente, com 63 adolescentes abrangidos pela Lei Tutelar Educativa, apresenta um dado novo. Em sua análise como critério de risco social, além de considerar os fatores habitacionais de infraestrutura, apresenta a constituição familiar como questão predominante. Conceitos como instabilidade familiar envolvendo divórcio, morte de um ou ambos os pais, história de maus-tratos e histórica criminal dos pais se apresentam como diferencial nos fatores que desencadeiam a delinquência infanto-juvenil ${ }^{60}$.

$\mathrm{Na}$ abordagem sobre a importância da família como fator de proteção na prevenção ao uso de substância psicoativa, os fatores psicossociais e existenciais aparecem relacionados à vulnerabilidade de adolescentes ${ }^{61}$. Ana Maria Bellani Migott aponta para muitas variáveis que atuam simultaneamente para influenciar a tendência de qualquer pessoa vir a usar drogas. Dentre as variáveis, estão a interação entre o agente (a droga), o sujeito (o indivíduo e a sociedade) e o meio (os contextos socioeconômico e cultural), o que corrobora a ideia dos mais variados dilemas em que está exposta a comunidade de risco social ${ }^{62}$. Estudos epidemiológicos concluíram que os problemas emocionais estão mais frequentes em grupos populacionais de baixos rendimentos e em áreas geográficas onde a desorganização social tende a prevalecer ${ }^{63}$.

Mas isso não é uma consequência apenas das periferias, dos bairros pobres. Janczura faz três ponderações que, embora não seja o foco deste trabalho, opõem-se à ideia de que é vulnerável quem é pobre ou quem mora em comunidade de periferia. Primeiro afirma que as definições de vulnerabilidade e risco social precisam ser entendidas quando associadas à diferentes contextos históricos sociais. Num segundo momento diz que, vulnerabilidade e risco social são conceitos distintos mas intrinsecamente relacionados, pois, enquanto risco se refere às condições fragilizadas

58 VARA DA INFÂNCIA, 2013, p. 2.

59 MARION-LÉON, Letícia. Percepção dos problemas da comunidade: influência de fatores sócio demográficos e de saúde mental. Cad. Saúde Pública, Rio de Janeiro, v. 23, n. 5, Mai 2007, p. 1089-1097.

60 LEMOS, Ida Timóteo. Risco psicossocial e psicopatologia em adolescentes com percurso delinquente. Aná. Psicológica, v. 28, n.1, Lisboa jan. 2010. Disponível em: http://www.scielo.oces.mctes.pt/scielo.php?pid=S087082312010000100009\&script=sci_arttext. Acesso em: 26 Set. 2014.

61 FREIRES, Irlan de Almeida; GOMES, Edésia Maria de Almeida. O Papel da família na prevenção ao uso de substâncias psicoativas. Revista Brasileira de Ciências da Saúde, v. 16, n. 1, p. 99-104.

62 MIGOTT, Ana Maria Bellani. Dependência química: problema biológico, psicológico ou social? In: MOTA, L A. São Paulo: Paulus; 2007. (Coleção Questões Fundamentais da Saúde, 12). Cad. Saúde Pública, Rio de Janeiro, v. 24, n. 3, Mar. 2008.

63 ORNELAS, José. Psicologia comunitária origens e fundamentos. Análise Psicológica, v. 3, n. 15, 1997, p. $375-388$.

Protestantismo em Revista | São Leopoldo | v. 45, n. 02 | p. 20-36| Jul./dez. 2019

Disponível em: <http://periodicos.est.edu.br/index.php/nepp> 
da sociedade tecnológica contemporânea, vulnerabilidade identifica a condição dos indivíduos nessa sociedade. Outro dado importante é que a autora analisa a sociedade pós-industrial como sociedade de risco, devido aos efeitos que a tecnologia e a globalização econômica produziram ${ }^{64}$.

O que fazer diante dessa situação de vulnerabilidade? Quais são as propostas de intervenção? Para considerar a Teologia Prática como interventora na potencialização do indivíduo, atuando enquanto porta-voz da esperança, assunto que nos deteremos no próximo tópico, é necessário um deslocamento tecnicista e biológico no modo de conceber e analisar a questão saúde/doença e sua respectiva intervenção.

Nessa perspectiva, Travesso-Yépez e Pinheiro, a partir de uma pesquisa-intervenção num bairro de periferia de Natal-RN, fazem uma crítica ao modelo unidimensional de saúde das instituições sociais, cuja tendência é garantir a sobrevivência de crianças e adolescentes, cuidando dos denominados problemas orgânicos, desconsiderando os aspectos psicológicos e socioambientais $^{65}$. Foi observado, a partir de trabalhos prévios no bairro, o alto índice de vulnerabilidade de adolescentes ligados a um contexto social perpassado pela precariedade de serviços de infraestrutura, alto índice de evasão escolar, relações familiares fortemente marcadas pela hierarquia de gênero e de geração, de perspectivas e oportunidades acadêmicas e profissionais ${ }^{66}$. Segundo as autoras, o contexto socioeconômico potencializa o risco social e prejudica o pleno desenvolvimento do ser humano, desdobrando-se para os atos de violência:

Esta situação, caracterizada pela violação dos direitos legalmente assegurados a crianças e adolescentes brasileiros há mais de dez anos, limita a consolidação de projetos de vida que transcendam os tradicionais papéis sexuais e a inserção no mercado informal de trabalho, gerando um ciclo de reprodução da pobreza e a potencialização dos riscos aos qual esse segmento populacional encontra-se exposto, particularmente os decorrentes das diferentes formas de violência e exclusão social, com restrito acesso aos recursos materiais ou simbólicos necessários ao seu pleno desenvolvimento. Observa-se que a violência, em todas as suas manifestações, vitimiza particularmente os grupos mais fragilizados dessas camadas sociais, como mulheres, crianças e adolescentes. ${ }^{67}$

Deduz-se, a partir do exposto, que o modo de intervenção nessas comunidades depende de um conjunto de fatores que estão além do tecnicismo biológico e organicista, pois a constituição humana é produto tanto dos determinantes psíquicos quanto sociais, sendo estes indissociáveis. Os determinantes sociais produzem um efeito psicológico que não pode ser compreendido apenas na sua dimensão individual e que não se pode deixar de ver como as questões sociais e econômicas influenciam a forma como os indivíduos se organizam em sociedade ${ }^{68}$.

Logo, o sofrimento não é visto como algo interno do homem, mas como algo construído a partir da relação do homem com o mundo material e social, mundo que só existe pela atividade humana, produzido por uma história de desigualdades e injustiças sociais, vivenciado pelo indivíduo, mas que tem origem nas relações intersubjetivas constituídas socialmente ${ }^{69}$. Por isso a necessidade de prática que intervenha no modo de existir coletivamente.

64 JANCZURA, 2012, p. 301-308.

65 TRAVERSO-YEPEZ, M. T.; PINHEIRO, V. S. Adolescência, saúde e contexto social: esclarecendo práticas. Psicologia \& Sociedade, v. 14, n. 2, jul./dez, 2002, p. 133-147.

66 TRAVERSO-YEPEZ; PINHEIRO, 2002, p. 135.

67 TRAVERSO-YEPEZ; PINHEIRO, 2002, p. 135.

68 COSTA, Liana Fortunato; BRANDAO, Shyrlene Nunes. Abordagem clínica no contexto comunitário: uma perspectiva integradora. Psicologia \& Sociedade, v. 17, n. 2, maio/ago. 2005, p. 33-41.

69 COSTA; BRANDÃO, 2005, p. 35.

Protestantismo em Revista | São Leopoldo | v. 45, n. 02 | p. 20-36| Jul./dez. 2019

Disponível em: <http://periodicos.est.edu.br/index.php/nepp> 
Quanto a isso, Ana Cristina Laurell analisa o fenômeno saúde/doença como processo social. A questão central de seu texto é discutir se a doença é de cunho biológico ou social. Questiona-se o paradigma médico-biológico, que vê a doença apenas pelo olhar biológico individual, levantando a possibilidade para um novo método de intervenção, neste caso, de novas práticas sociais. No entender da autora, no cenário latino-americano, a medicina clínica não oferece solução satisfatória para a melhoria das condições de saúde da coletividade ${ }^{70}$.

Fica implícita, por meio da literatura, a fragilidade emocional das pessoas. Percebe-se que a violação dos direitos humanos, a falta de infraestrutura e o contexto socioeconômico comprometem o desenvolvimento humano, potencializando o risco social. Constata-se que a questão de risco social não envolve apenas as periferias, mas também a sociedade pós-industrial, com suas respectivas perdas para a humanidade envolvendo a violência, a instabilidade emocional e o envolvimento com substâncias psicoativas, demandando ações preventivas no resgate da dignidade humana. Nesse sentido, a doença é vista como fenômeno coletivo e não como algo apenas biológico, por isso, a Teologia Prática poderá auxiliar no pleno desenvolvimento humano por meio de sua ação eclesiológica no contexto de risco social, assunto que nos deteremos nesse momento.

\section{A Teologia Prática e sua Ação Eclesiológica: Uma Porta de Esperança}

Para uma ação eclesiológica relevante no século XXI e, especificamente, no contexto de comunidade de risco social, é necessário uma revisão de conceitos e funcionalidade acerca do papel da Igreja na sociedade contemporânea. Já foi considerado que a Teologia Prática caminha em diálogo com o contexto a qual está inserida, ou seja, é discurso de ação cristã no mundo. Constataram-se os diversos dilemas existenciais presentes na comunidade de risco social, tornando salutar uma reflexão da Teologia Prática na ação eclesiológica como porta de esperança, contribuindo para a potencialização do desenvolvimento humano. Essa é a proposta deste tópico.

Octávio H. Ribeiros de Medeiros afirma que a religião permeia os aspectos concretos da vida dos indivíduos envolvendo tanto as dimensões de princípios e valores quanto nas situações contingentes que surgem no quotidiano das pessoas ${ }^{71}$.

Por sua vez, Martha Caroline Henning e Carmem L. O. O. Moré, numa revisão de literatura de 127 artigos, analisando a interface temática entre psicologia e religião, afirmam que a espiritualidade se faz presente nos atendimentos clínicos de Psicologia, pois a sua influência não se restringe ao contexto sociocultural, mas também na constituição da subjetividade do indivíduo, expressa em crenças, valores, emoções e comportamentos a elas relacionados. Há uma inteligência existencial/espiritual no indivíduo que proporciona, dentre outras capacidades, a habilidade de utilizar recursos espirituais para resolver problemas na vida.

Desta feita, a experiência religiosa contribui para o crescimento pessoal, a tolerância nos relacionamentos interpessoais, da inserção em grupos sociais, do autoconhecimento e desenvolvimento da empatia. Por isso, o universo religioso exerce uma função de inserção e/ou

70 LAURELL, Ana Cristina. La salud-enfermedad como proceso social. Revista Latinoamericana de Salud, México, v. 2, 1982, p. 7-25. Trad. E. D. Nunes. Disponível em: http://fopspr.files.wordpress.com/2009/01/saudedoenca.pdf. Acesso em: 25 Set. 2014.

71 MEDEIROS, Octávio H. Ribeiros de. Religião e problema moral: Segmentação social e crescente individuação. Actas dos ateliers do Vo Congresso Português de Sociologia - Sociedades Contemporâneas: Reflexividade e Acção Atelier: Quotidiano, Crenças e Religiosidades. Disponível em: http://www.aps.pt/cms/docs prv/docs/DPR4628ef1b1872c 1.pdf. Acesso em: 25 Jul. 2014.

Protestantismo em Revista | São Leopoldo | v. 45, n. 02 | p. 20-36| Jul./dez. 2019

Disponível em: <http://periodicos.est.edu.br/index.php/nepp> 
reinserção do indivíduo em um grupo e meio sociocultural motivador e dotado de sentido ${ }^{72}$. É nessa perspectiva que se dará a urgência da Teologia Prática no contexto de comunidade de risco social, mediando os conflitos, potencializando o ser humano e descortinando os horizontes da existência numa atitude de inclusão por meio da ação eclesiológica. Para isso ocorrer é necessária uma eclesiologia que trabalhe as reflexões teológicas próximas à realidade humana. Uma igreja da esperança. Essa é a proposta de Jürgen Moltmann em sua principal obra Teologia da Esperança ${ }^{73}$.

O eixo epistemológico dessa teologia é a escatologia cristã, todavia, a sua proposta não é dogmática. É uma crítica à ação eclesiológica que, ao longo da história, transformou a escatologia numa ação doutrinária, tornando mais institucional do que prática, perdendo a sua relevância no contexto social ${ }^{74}$. Para corrigir esse erro de distorção propõe-se a reflexão de uma escatologia alinhada à esperança cristã. Desta forma, a escatologia deixa de ser simplesmente parte da doutrina cristã e se apresenta a partir das reflexões sobre a revelação de Deus, a ressurreição de Cristo, a missão da fé e a história como um ponto de equilíbrio para os dilemas da vida. Assim a esperança "[...] não vê na ressurreição de Jesus Cristo a eternidade do céu na terra, mas o futuro da própria terra na qual está plantada sua cruz. Em Cristo, ela reconhece o futuro da humanidade, pela qual ele morreu. Por isso, para ela, a cruz é a esperança da terra"75.

É nesta perspectiva que o humano é acolhido. Uma vez que o sentido escatológico abre novas portas, impulsiona para frente ${ }^{76}$, "...] crer significa, na realidade, transpor fronteiras, transcender, estar em êxodo" ${ }^{\prime 77}$. Mas isso não muda a realidade de caos, de tribulação, muito menos amenizam os dilemas da comunidade de risco social. No entanto, pelo fato da fé se apoiar na esperança,

[...] a fé transcende essas realidades, pois não se refugia no céu nem na utopia e, tampouco, sonha estar em uma outra realidade. Ela apenas pode transpor os limites da vida humana, cercada por muros de sofrimento, pecado e morte, onde estes foram realmente derrubados; apenas pela aceitação do Cristo ressuscitado, do sofrimento, da morte, do abandono de Deus e do túmulo, ela ganha perspectiva para a amplidão em que não há mais opressão, para a liberdade e para o gozo. ${ }^{78}$

Por esse viés a história deixa de ser fatalidade, como no modo de pensar cosmológicomecanicista, para uma história de esperança e de abertura, conforme a teologia cristã. Por isso,

\footnotetext{
"História" não pode significar para a teologia cristã pregar, por sua vez, a verdade de Deus em conexão com as antigas experiências de destino e de acaso e na aceitação delas, mas sim, subordinar este mesmo mundo ao processo da promessa e da esperança que impele para frente. ${ }^{79}$
}

72 HENNING, Martha Caroline; MORÉ, Carmem L. O. O. Religião e psicologia: análise das interfaces temáticas. Revista de Estudos da Religião, Dez. 2009, p. 84-114.

73 MOLTMANN, Jürgen. Teologia da esperança: estudos sobre os fundamentos e as consequências de uma escatologia cristã. São Paulo: Editora Teológica; Edições Loyola, 2005, p. 55-127. Há críticas veementes ao cristianismo que se acomodou à Religião de Estado, perdendo a sua autocrítica e relevância para a sociedade.

74 MOLTMANN, 2005, p. 29-31. Nestas páginas o autor transfere, num posicionamento crítico, o conceito de escatologia presa às amarras da dogmática cristã, vistos pela ótica do "último dia", para a escatologia da promessa e sua respectiva aplicabilidade no contexto humano.

75 MOLTMANN, 2005, p. 36.

76 MOLTMANN, 2005, p. 30.

77 MOLTMANN, 2005, p. 34.

78 MOLTMANN, 2005, p. 34.

79 MOLTMANN, 2005, p. 127.

Protestantismo em Revista | São Leopoldo | v. 45, n. 02 | p. 20-36| Jul./dez. 2019

Disponível em: <http://periodicos.est.edu.br/index.php/nepp> 
Logo, o eixo da ação eclesiológica e sua mensagem estarão no âmbito da existência humana, o que faz coro com a Teologia Prática, pois a esperança "[...] faz da comunidade cristã uma fonte de impulsos sempre novos para a realização do direito, da liberdade e da humanidade aqui mesmo, à luz do futuro predito e que virá" ${ }^{80}$. É nesse processo que ocorre a humanização do indivíduo. Há uma relação entre a prova da existência de Deus com a existência humana, com o mundo e a partir de Deus mesmo enquanto prova ontológica ${ }^{81}$. Nesse sentido, o Deus de Jesus Cristo é o Deus de todos os seres humanos e de toda a realidade. Essa é a chave hermenêutica de missão eclesiológica proposta por Moltmann e que conduz a humanização do indivíduo. Por isso a hermenêutica do apostolado e os testemunhos das narrativas bíblicas: apontar as promessas de Deus, no sentido escatológico de promessa e esperança, trazendo significado para a existência humana ${ }^{82}$. Os testemunhos bíblicos, estudados na perspectiva da história da missão,

[...] pode abrir para o ser humano de hoje novas possibilidades, perspectivas e metas por intermédio da apresentação daquele evento que prepara o caminho para o futuro escatológico. Para isso, é necessário tomar o ser humano em seu próprio ser no contexto, e não separadamente, da presente constelação da sociedade humana, para possibilidades da missão para o futuro. ${ }^{83}$

Esse é o caminho de Jesus Cristo, uma Cristologia terapêutica que, para evitar uma crise de identidade, precisa afastar-se tanto de uma cristologia eclesiástica com o critério de biblicidade quanto da hermenêutica de efeitos ${ }^{84}$. A solução é uma cristologia apologética e terapêutica. Enquanto aquela procura dar uma resposta à razão da esperança, esta "[...] apresenta a salvação que Cristo traz de modo salutífero na miséria da atualidade" 85 . Logo, enfatiza-se a unidade da cristologia com a soteriologia. Por este ângulo, a soteriologia não é vista apenas metafisicamente, mas é a salvação toda e a salvação do todo, repercutindo no âmbito social, político, econômico, além da miséria humana no sentido individual. Nessa perspectiva leva-se em consideração a real miséria das pessoas, sem perder de vista o horizonte escatológico da salvação do todo ${ }^{86}$.

Por esse caminho deve trilhar a apresentação do evangelho no contexto de comunidade de risco social, em uma inter-relação entre proclamação e missão. O evangelho, na dimensão messiânica, é liberdade do êxodo, alegria, justiça e comunhão. "Seu público são os pobres, miseráveis, doentes e desesperançados como aqueles que mais sofrem sob o afastamento de Deus e a inimizade dos homens" 87 .

Assim o Reino de Deus não é analisado quialisticamente ${ }^{88}$, muito menos enquanto estado utópico. Afasta-se, também, de um conceito de domínio de Javé no sentido apenas transcendente,

80 MOLTMANN, 2005, p. 37.

81 MOLTMANN, 2005, p. 340-352. A prova da existência de Deus é apresentada enquanto chave hermenêutica da missão. Nesse sentido, não há como negar a existência de Deus, se a existência humana clama por ela.

82 MOLTMANN, 2005, p. 353-361.

83 MOLTMANN, 2005, p. 360-361.

84 MOLTMANN, Jürgen. O caminho de Jesus Cristo: cristologia em dimensões messiânicas. São Paulo: Ed. Academia Cristã, 2009, p. 81-84. O critério de biblicidade é um termo usado pelo autor para apresentar uma cristologia eclesiológica enquanto hermenêutica de origem, cujo enunciado cristológico perpassa por sua origem histórica e objetiva, dissociado da miséria humana, necessitando vir acompanhada pela hermenêutica de efeito. Todavia, tanto o critério de biblicidade quanto a hermenêutica de efeito, se olhados unilateralmente, provocam uma crise de identidade na cristologia.

85 MOLTMANN, 2009, p. 81.

86 MOLTMANN, 2009, p. 83.

87 MOLTMANN, 2009, p. 156

88 Uma expressão filosófica que reduz a existência e toda a realidade ao nada. Tudo é passageiro e efêmero.

Protestantismo em Revista | São Leopoldo | v. 45, n. 02 | p. 20-36| Jul./dez. 2019

Disponível em: <http://periodicos.est.edu.br/index.php/nepp> 
sem relação com a obra criada. Por meio de Jesus Cristo, o Reino de Deus desce à terra, agindo no quotidiano das pessoas, numa ação recriadora e vivificadora de Deus ${ }^{89}$, conferindo dignidade aos pobres ${ }^{90}$. "Por isso está em primeiro plano para Jesus a preocupação com a pobreza, doença, possessão demoníaca, abandono, e não a preocupação com as doutrinas dos fariseus e saduceus" ${ }^{\prime \prime}$.

Esse é um aspecto importante da prática eclesiológica no contexto de comunidade de risco social. Por vezes, essa prática está mais voltada para com a doutrina e seus liames institucionais do que para com a indignidade em que vive o ser humano, esquecendo-se de tornar o Reino de Deus o "reino messiânico dos pobres" 92 . Nessa direção, será possível uma ação eclesiológica relevante e diferenciada, estendendo-se para os mais variados contextos de miséria humana, promovendo a humanização do indivíduo, a socialização da humanidade e a paz para toda a criação, dialogando com a sociedade contemporânea ${ }^{93}$.

Para tanto, será necessário que se reveja o conceito de missão do evangelho na contemporaneidade como propõe John Stott. É preciso desarticular, na visão tradicional cristã, o conceito de missão e evangelismo. Nesse conceito a missão cristã restringia-se à apresentação de um plano de salvação, em que o mundo é considerado um lugar inabitável para o cristão. Mas, de igual modo, é imprescindível rever o conceito de missão apresentado pelo movimento ecumênico, que vê a missão como o estabelecimento da shalom na sociedade ${ }^{94}$.

O que fazer para dirimir esse polo de tensão conceitual quanto à missão cristã? A partir do exemplo de Jesus Cristo, a proposta é o evangelismo e a responsabilidade social numa atmosfera de serviço. Essa é a proposta do Pacto de Lausanne ${ }^{95}$. Assim, a Igreja deixa de ser uma comunidade de adoração e testemunho, para ser uma comunidade de ação, estendendo-se para os contextos de miséria do ser humano, tanto do ponto de vista local quanto nacional ${ }^{96}$. Nesta acepção, "[...] diante da tensão que está posta pela coexistência de polos antagônicos como violência e paz, entre outras contradições inerentes a estrutura social" ${ }^{\prime 97}$ a igreja necessita urgentemente,

Refletir sobre sua missão no mundo - missão de serviço (Mc 10.42-45). - Perceber o serviço ao próximo como serviço a Deus (Mt 25.41-46). - Vivenciar a missão integral (At 2.42-47). Ir ao encontro da humanidade sofrida (Jo 17.18) - Aproximando-se de sua comunidade;

89 MOLTMANN, 2009, p. 157-160.

90 MOLTMANN, 2009, p. 160-164. No Novo Testamento, "os pobres" são as "não-pessoas", os "sub-homens", os desumanizados, "material humano" (p. 161).

91 MOLTMANN, 2009, p. 160.

92 MOLTMANN, 2009, p. 164.

93 KUZMA, Cezar Augusto. A esperança cristã na 'Teologia da Esperança: 45 anos da Teologia da Esperança de Jürgen Moltmann: sua história, seu caminho, sua esperança. Revista Pistis \& Práxis. Teol. Pastoral. Curitiba, v. 1, n. 2, jul./dez. 2009, p. 443. Na exposição desse autor é pontuada a relação da Teologia da Esperança na Teologia da Libertação enquanto proposta de evangelização na América Latina.

94 STOTT, John. A missão cristã no mundo moderno. Viçosa, MG: Ultimato, 2010, p. 17-41. Quanto à discussão da missão cristã houve um polo de tensão entre a interpretação vertical do evangelho, com ênfase na ação salvadora na vida dos indivíduos e a interpretação horizontal do evangelho, que focava principalmente nos relacionamentos humanos no mundo.

95 STOTT, 2010, p. 29. Pacto de Lausanne foi um documento elaborado no Congresso Mundial de Evangelização em Lausanne, na Suíça, em 1974, com o objetivo de estudar e compreender as Escrituras e o movimento missiológico. A partir de então, entendeu-se que o evangelho afeta todas as dimensões da vida, tanto no aspecto da salvação individual quanto na visão holística do ser humano. Nesse sentido, a missão cristã tem como objetivo o envolvimento da igreja no mundo.

96 STOTT, 2010, p. 36-41.

97 MELO, Delaine. Violência e paz: há esperança. In: Saúde, violência e graça: a missão integral e os desafios para igreja. Viçosa: Ultimato, 2003, p. 33.

Protestantismo em Revista | São Leopoldo | v. 45, n. 02 | p. 20-36| Jul./dez. 2019

Disponível em: <http://periodicos.est.edu.br/index.php/nepp> 
conhecendo sua realidade vivencial; discutindo com a comunidade sobre necessidades e prioridades; planejando ações para modificação da realidade; acompanhando a comunidade para fortalecer a caminhada. ${ }^{98}$

Agindo assim, a Igreja deixará de ser contemplativa, embora esta faça parte de sua constituição, para ser relevante. Na comunidade de risco social a intervenção eclesiológica, mediada por uma Teologia Prática na Teologia da Esperança, dar-se-á no sentido de combater a violência doméstica, auxiliar na prevenção quanto ao uso de substâncias psicoativas, potencializar a ação humana e restaurar o coração ferido. Trata-se de uma esperança para os fracos e oprimidos.

\section{Considerações Finais}

A sociedade contemporânea apresenta muitos desafios para o poder público. Ao mesmo tempo em que se apresenta o progresso, juntos vêm os mais variados dilemas. Com o intuito de dirimir o impacto dessa aldeia globalizada na condição da vida humana é necessário o diálogo entre todas as instâncias, instituições governamentais e não governamentais, no objetivo de promover o bem-estar social. Por esse viés é apresentada a Teologia Prática, surgindo para diminuir a distância entre o academicismo teológico e a ação pastoral, atuando a partir do contexto ao qual está inserida.

Por contexto, foi analisada a comunidade de risco social, que não envolve apenas as periferias, mas, de igual modo, a sociedade pós-industrial. Constatou-se que a ausência de infraestrutura, a violação dos direitos humanos e o contexto socioeconômico agravam a condição de vida humana, provocando instabilidade emocional, o envolvimento com substâncias psicoativas, dentre outras questões. À vista disso, a doença foi considerada como fenômeno coletivo e não como algo apenas biológico, por isso, a necessidade e urgência de uma Teologia que promova a restauração, auxiliando no pleno desenvolvimento humano.

Considerando os desafios da sociedade contemporânea e o âmbito da comunidade de risco social, a ação eclesiológica, mediada pela Teologia Prática, se voltará para o contexto o qual está inserida. A sua ação missionária e evangelística contemplará a miséria humana, os seus dilemas e problemas sociais. Por isso será prática e não dogmática. Nesse sentido, diante dos problemas como a violência doméstica, a desestruturação familiar, a perda da autoimagem, a eclesiologia visa a potencialização do ser humano, promovendo a saúde integral do indivíduo no contexto de comunidade de risco social.

\section{Referências}

BALMAN, Zygmunt. Tempos líquidos. Rio de Janeiro: Zahar, 2007.

BERKHOF, Louis. Teologia sistemática. 2. ed. Campinas: Luz Para o Caminho, 1990.

BRASIL $^{1}$ 2018. Brasil mantém tendência de avanço no desenvolvimento humano, mas desigualdades persistem. Posted on 14 de Setembro de 2018. Disponível em: http://www.br.undp.org/content/brazil/pt/home/presscenter/articles/2018/brasil-mantemtendencia-de-avanco-no-desenvolvimento-humano--mas.html. Acesso em: 14 Set. 2018.

98 MELO, 2003, p. 33-34.

Protestantismo em Revista | São Leopoldo | v. 45, n. 02 | p. 20-36| Jul./dez. 2019

Disponível em: <http://periodicos.est.edu.br/index.php/nepp> 
BRASIL ${ }^{2} 2018 . \quad$ Sobre PNUD. Disponível em: http://www.br.undp.org/content/brazil/pt/home/operations/about undp.html. Acesso em: 14 Set. 2018.

BUHR, João Rainer. Teologia pública. Revista Batista Pioneira, vol. 7, n. 1, Junho/2018.

CAMPOS, Maria Tereza Freitas. Psicologia Comunitária: da solidariedade a autonomia. Petrópolis: Vozes, 2007.

COSTA, Liana Fortunato; BRANDAO, Shyrlene Nunes. Abordagem clinica no contexto comunitário: uma perspectiva integradora. Psicologia \& Sociedade; 17 (2): 33-41; Mai/Ago., 2005.

DAGG, John L. Manual de teologia. 2. ed. São Paulo: Editora Fiel,1998.

DIETRICH, Luiz José. A descolonização da Bíblia, da "Palavra de Deus": O desafio primeiro e urgente para uma teologia descolonial. ReBiblica, Porto Alegre, v. 1, n. 1, p. 19-37, jan.-jun. 2018.

FEUERBACH, Ludwig. A essência do cristianismo. Petrópolis, RJ: Vozes, 2007.

FRAAS, Hans-Jurgen. A religiosidade humana: compêndio de psicologia da religião. 2. ed. São Leopoldo: Sinodal, 1997.

FREIRES, Irlan de Almeida. GOMES, Edésia Maria de Almeida. O Papel da família na prevenção ao uso de substâncias psicoativas. Revista Brasileira de Ciências da Saúde, Volume 16, Número 1, p. 99 104.

HAN, Byung-Chul. Sociedade do cansaço. Petrópolis: Vozes, 2015.

HENNING, Martha Caroline. MORÉ, Carmem L. O. O. Religião e psicologia: análise das interfaces temáticas. Revista de Estudos da Religião, dezembro, 2009, p. 84-114.

$\mathrm{HOCH}$, Lothar Carlos. O lugar da teologia prática como disciplina teológica. SCHNEIDERHARPPRECHT, Christoph; ZWETSCH, Roberto E.; HOCH, Lothar Carlos. Teologia prática no contexto da América Latina. 3. ed. revista e ampliada São Leopoldo, RS: Sinodal, 2011. p. 23-35.

JANCZURA, Rosane. Risco ou vulnerabilidade social? Textos \& Contextos (Porto Alegre), v. 11, n. 2, Ago./Dez. 2012, p. 301-308.

KUZMA, Cezar Augusto. A Esperança cristã na 'Teologia da Esperança: 45 anos da Teologia da Esperança de Jürgen Moltmann: sua história, seu caminho, sua esperança. Revista Pistis \& Práxis, Teologia Pastoral, Curitiba, v. 1, n. 2, Jul./Dez. 2009, p. 443-467.

LAURELL, Ana Cristina. A saúde doença como processo social. "La salud-enfermedad como proceso social". Revista Latinoamericana de Salud, México, 2, 1982, pp. 7-25. Disponível em: http://fopspr.files.wordpress.com/2009/01/saudedoenca.pdf. Acesso em: 25 Set. 2014.

LEMOS, Ida Timóteo. Risco psicossocial e psicopatologia em adolescentes com percurso delinquente. Aná. Psicológica v.28 n.1 Lisboa Jan. 2010. Disponível em: http://www.scielo.oces.mctes.pt/scielo.php?pid=S0870-82312010000100009\&script=sci_arttext.

Acesso em: 26 Set. 2014.

MARION-LÉON, Letícia. Percepção dos problemas da comunidade: influência de fatores sócio demográficos e de saúde mental. Cad. Saúde Pública, Rio de Janeiro, 23(5), Maio 2007, p. 10891097.

MEDEIROS, Octávio H. Ribeiros de. Religião e problema moral: Segmentação social e crescente individuação. Actas dos ateliers do $\bigvee o$ Congresso Português de Sociologia - Sociedades Contemporâneas: Reflexividade e Acção Atelier: Quotidiano, Crenças e Religiosidades. Disponível em: http://www.aps.pt/cms/docs prv/docs/DPR4628ef1b1872c 1.pdf. Acesso em: 25 Jul. 2014.

Protestantismo em Revista | São Leopoldo | v. 45, n. 02 | p. 20-36| Jul./dez. 2019

Disponível em: <http://periodicos.est.edu.br/index.php/nepp> 
MELO, Delaine. Violência e paz: há esperança. In: Saúde, violência e graça: a missão integral e os desafios para igreja. Viçosa: Ultimato, 2003.

MIGOTT, Ana Maria Bellani. Dependência química: problema biológico, psicológico ou social? São Paulo: Paulus, 2007.

MOTA LA. (Coleção Questões Fundamentais da Saúde, 12). Cad. Saúde Pública, v. 24, n. 3, Mar. 2008.

MIRANDA, Valtair A. Fundamentos da teologia bíblica. São Paulo: Mundo Cristão, 2011.

MOLTMANN, Jürgen. O caminho de Jesus Cristo: cristologia em dimensões messiânicas. São Paulo: Ed. Academia Cristã, 2009.

MOLTMANN, Jürgen. Teologia da esperança: estudos sobre os fundamentos e as consequências de uma escatologia cristã. 3. ed. São Paulo: Editora Teológica; Edições Loyola, 2005.

MORIN, Edgar. As certezas são uma ilusão por CNRS / Le Journal por Francis Lecompte - 09.04.2020. Fronteiras do Pensamento. Disponível em: https://www.fronteiras.com/entrevistas/edgar-morinas-certezas-sao-uma-ilusao. Acesso em: 09 Mai. 2020.

ORNELAS, José. Psicologia comunitária origens e fundamentos. Análise Psicológica (1997), 3 (XV), p. 375-388.

PUC-RIO, Certificação Digital No 0220971/CA. Teologia e interdisciplinaridade. Disponível em: https://www.maxwell.vrac.puc-rio.br/10454/10454 4.PDF. Acesso em: 18 Fev. 2020.

RODRIGUES, Alessandro. Teologia sistemática no horizonte pós-moderno: um novo lugar para a linguagem teológica. São Paulo: Editora Vida, 2007.

ROTTO, Júlio Cezar de Paula. O eternamente novo no mesmo evangelho: implicações teológicopastorais para a evangelização das tribos urbanas de rosto underground. Tese doutorado em teologia - Pontifícia Universidade Católica do Rio de Janeiro, Departamento de Teologia, 2016. Disponível em: https://www.maxwell.vrac.puc-rio.br/27184/27184.PDF. Acesso em: 20 Mai. 2020.

SANCHES, Sidney de Moraes. A contextualização da teologia: conceitos, história, tensões, métodos e possibilidades. Revista Tecer, Belo Horizonte, vol. 2, no 3, Nov. 2009.

SMITH, Ralph L. Teologia do antigo testamento: história, método e mensagem. São Paulo: Vida Nova, 2001.

SOARES, Maria de Lourdes. A exclusão de comunidades em situação de vulnerabilidade e de risco social: 0 caso da comunidade do S. Disponível em: http://www.cibs.cbciss.org/arquivos/A\%20EXCLUSIO\%20DE\%20COMUNIDADES\%20EM\%20SITUAC AO\%20DE\%20VULNE. Acesso em: 25 Jul. 2014.

STOTT, John. A missão cristã no mundo moderno. 2. ed. Viçosa, MG: Ultimato, 2010.

TRAVERSO-YEPEZ, M.T.; PINHEIRO, V.S. Adolescência, saúde e contexto social: esclarecendo práticas. Psicologia \& Sociedade; 14 (2), Jul./Dez. 2002, p. 133-147.

VILLAS BOAS, Alex. Em busca de uma teologia pública da saúde. Horizonte, Belo Horizonte, v. 14, n. 41, Jan./Mar. 2016, p. 89-121.

ZABATIERO, Júlio Paulo Tavares. A Teologia Prática e seu lugar na Igreja. REVISTA TEOLOGIA PRÁTICA - FATE-BH, Belo Horizonte, v. 1, n.1, 2/2002, p. 7-15.

ZABATIERO, Júlio Paulo Tavares. Fundamentos da teologia prática. São Paulo: Mundo Cristão, 2005.

Protestantismo em Revista | São Leopoldo | v. 45, n. 02 | p. 20-36| Jul./dez. 2019

Disponível em: <http://periodicos.est.edu.br/index.php/nepp> 